\title{
Docência e Processos de Escolarização: Desafios nos Anos Iniciais do Ensino Fundamental
}

\author{
Luciane Guisso ${ }^{1}$ \\ ${ }^{1}$ Universidade Federal de Santa Catarina, SC, Brasil.
}

\author{
Marivete Gesser $^{1}$ \\ ${ }^{1}$ Universidade Federal de Santa Catarina, SC, Brasil.
}

\begin{abstract}
Resumo: O objetivo desta pesquisa consistiu em compreender, com os professores, os sentidos atribuídos aos desafios no processo de escolarização, nos anos iniciais do ensino fundamental. Para tanto, foi organizado um grupo focal, composto de 12 docentes, os quais tiveram seus relatos gravados, com o consentimento de cada um, em áudio e vídeo. Na sequência, esses relatos foram transcritos e analisados por meio da identificação dos núcleos de significação. Os indicadores localizados foram: relação e parceria com a família; características dos estudantes na atualidade; complexidade da função do educador; relação com a equipe pedagógica e com os colegas de trabalho; judicialização das práticas escolares e direitos dos estudantes. Os mesmos refletem o olhar dos professores para os problemas observados em seu fazer profissional cotidianamente. Percebe-se pouca reflexão em torno da própria organização da política educacional que afeta diretamente a formação e a capacitação docente, sua carga horária e salário. Todos esses aspectos trazem aos professores desafios diários com os quais estes profissionais precisam lidar, para manter-se no exercício da profissão.
\end{abstract}

Palavras-chave: Professores, Estudantes, Ensino Fundamental, Aprendizagem.

\section{Teaching and Schooling Processes: Challenges in the Early Years of Elementary School}

\begin{abstract}
The objective of this research was to understand, together with teachers, the meanings attributed to the challenges in the schooling process during the initial years of elementary school. To this end, a focus group composed of twelve teachers was organized. Teachers had their reports recorded in audio and video, with their consent. Reports were then transcribed and analyzed through the identification of meaning cores. The indicators found were: relationship and partnership with the family; characteristics of students today; complexity of the educator's role; relationship with the pedagogical staff and co-workers; judicialization of school practices and student rights. These indicators reflect teachers' view of about the problems observed in their daily work. There was little reflection on the very organization of educational policies that directly affects teachers' education and training, their workload, and salary. All these aspects present teachers with daily challenges, which these professionals need to deal with in order to remain in their profession.
\end{abstract}

Keywords: Teachers, Students, Elementary School, Learning. 


\title{
Docencia y Procesos de Escolarización: Desafíos en los Años Iniciales de la Educación Primaria
}

\begin{abstract}
Resumen: El objetivo de esta investigación consistió en comprender, junto con los maestros, los sentidos atribuidos a los desafíos en el proceso de escolarización en los años iniciales de la enseñanza fundamental. Para ello, se organizó un grupo focal, compuesto de doce maestros, los cuales tuvieron sus relatos grabados, con el consentimiento de cada uno, en audio y video. Posteriormente, estos relatos fueron transcritos y analizados por medio de la identificación de los núcleos de significación. Los indicadores encontrados fueron: relación y colaboración con la familia; las características de los estudiantes en la actualidad; complejidad de la función del educador; relación con el equipo pedagógico y con compañeros de trabajo; judicialización de las prácticas escolares y derechos de los estudiantes. Los mismos reflejan la visión de los maestros acerca de los problemas observados en su actuación profesional cotidianamente. Se percibe poca reflexión acerca de la propia organización de la política educativa que afecta directamente la formación y capacitación docente, su carga horaria y salario. Todos estos aspectos plantean a los maestros desafíos diarios, a que estos profesionales necesitan hacer frente para mantenerse en el ejercicio de su profesión.
\end{abstract}

Palabras clave: Maestros, Estudiantes, Educación Primaria, Aprendizaje.

\section{Introdução}

Atualmente, aponta-se para a (quase) universalização do ensino fundamental de estudantes em idade escolar. Em função da sua obrigatoriedade, conforme destacado nas reformas da educação brasileira a partir de 1990, a escola faz-se presente no cotidiano da grande maioria dos sujeitos das mais variadas classes sociais (Michels, 2006). Contudo, para atender a todos, considerando a diversidade dos estudantes, é necessário que sejam criados programas de educação que dialoguem com questões como as de gênero e étnico-raciais, com as especificidades da educação do campo e do ensino para estudantes com deficiências e altas habilidades (Kassari, 2016).

Baglieri, Beijoan, Broderick, Connor e Valle (2011) destacam a relevância de que o ensino, para garantir o acesso ao conhecimento a todos os estudantes, precisa ser pautado nos princípios de uma educação inclusiva. Esta deve ter como norte o rompimento do "mito da criança normal", o qual exclui as crianças que diferem do que tem sido instituído como norma de aprender e de estar no mundo pelo modelo biomédico. Para os autores, a educação inclusiva é entendida como uma educação que propicia a inclusão de todas as crianças no sistema educacional, por meio do rompimento das barreiras à aprendizagem e da ampla garantia da participação dos discentes. Ela deve ser voltada ao rompimento com as atividades discriminatórias e à criação de estruturas para reconhecer $\mathrm{e}$ valorizar a diversidade humana.

Salienta-se que, apesar de os números indicarem o acesso à escola, estudos apontam que, na prática, a organização escolar ainda não é universal para todos os estudantes, uma vez que nem todos conseguem, de fato, o sucesso escolar (Pletsch, 2009; Carvalho, 2013). Michels (2006) aborda que as mudanças nos sistemas e nas políticas educacionais, provocadas pelas políticas neoliberais, introduziram estratégias como descentralização no ensino, reorganização curricular, autonomia das escolas e novas responsabilidades aos professores. Dessa maneira, vivencia-se um desalinhamento entre as propostas dos programas de educação citados e os desafios sentidos pelos docentes em suas práticas cotidianas, o que contribui para o tensionamento e as angústias entre os envolvidos, no contexto escolar (Souza, 2006).

Estudos realizados com professores indicam que os desafios vivenciados no processo de escolarização dos estudantes são diversos, como: o questionamento do papel do professor (Camargo, 2004); a relação e a parceria com a família (Magalhães, 2004; Tavares, \& Nogueira, 2013); e o despreparo sentido pelos docentes para lidar com os comportamentos dos estudantes (Dias, Pereira, \& Borsel, 2013; Oliveira, Bragnolo, 
\& Souza, 2014). Além desses, mencionam-se, ainda, o desafio para trabalhar com questões de gênero e de sexualidade (Gesser, Oltramari, \& Panison, 2015) e questões relacionadas à deficiência e/ou às necessidades educacionais especiais (Pinto, \& Morgado, 2012; Fantacini, \& Dias, 2015). No entanto, nota-se que os trabalhos pouco indicam reflexões de um âmbito maior da própria organização da política educacional e o reflexo disso no trabalho dos docentes.

Com base no exposto, considera-se que compreender os desafios vivenciados por professores, no processo de escolarização de estudantes do ensino fundamental, pode contribuir para a elaboração de programas de formação docente voltados para as necessidades desse público. Também, pode visibilizar a importância de a escola criar espaços nos quais os docentes possam, juntos, construir estratégias de enfrentamento coletivo dos desafios vivenciados (Gesser, Oltramari, Cord, \& Nuernberg, 2012). Assim, o objetivo do presente trabalho corresponde a compreender, com os professores, os sentidos atribuídos aos desafios no processo de escolarização, nos anos iniciais do ensino fundamental de uma escola pública.

Quanto ao referencial teórico-metodológico, este estudo foi pautado na Psicologia Histórico-Cultural (Vygotsky, 2000). Essa perspectiva aponta para a compreensão do sujeito como constituído nas relações intersubjetivas, por meio do processo de mediação. Ademais, considera que, para o entendimento do sujeito, é importante analisar o contexto e os processos de apropriação dos signos sociais.

\section{Método}

Este artigo refere-se a um recorte da pesquisa intitulada "Sentidos atribuídos às dificuldades no processo de escolarização por professoras/es dos anos iniciais do ensino fundamental", no qual optou-se por abordar o núcleo de significação "desafios no processo de escolarização de estudantes". Essa pesquisa se caracteriza como de cunho qualitativo, a qual foi realizada em uma escola pública, localizada em uma capital do Sul do Brasil. Essa escola atende a estudantes do $1^{\circ}$ ano do ensino fundamental até o $3^{\circ}$ ano do ensino médio. Para a obtenção das informações, foram utilizados a observação participante e o grupo focal.

A observação participante ocorreu no período compreendido entre início de março e final de abril de 2016, tendo como finalidade conhecer a escola, estabelecer um canal mais próximo de comunicação e cons- truir vínculo com os docentes. Os professores foram ouvidos individualmente, e, quando pertinente, em pequenos grupos, e puderam falar sobre suas angústias e desafios enfrentados no processo de escolarização. Foi ouvido um total de 22 professores, ao longo do processo de observação participante, os quais, na sequência, foram convidados a participar da próxima etapa da pesquisa que consistiu no grupo focal.

O grupo focal foi realizado no mês de maio de 2016, em uma sala da escola e contou com a participação de 12 dos 22 professores da escola, ouvidos na primeira etapa. Durante a realização do grupo focal, foi possível a produção de reflexões e de trocas que dificilmente aconteceriam fora daquele contexto, corroborando o que já fora apontado por Kind (2004) e Carlini-Cotrim (1996), referente à importância do grupo focal.

Foram utilizados uma câmera de vídeo e dois gravadores, dispostos em locais apropriados, na sala, para assegurar a gravação das falas do grupo. Na efetivação do grupo focal, contou-se com a presença de um observador externo que realizou anotações em relação à dinâmica do grupo e que estava familiarizado com o tema de pesquisa, conforme propõe Kind (2004). O registro foi efetivado com a concordância dos participantes, assegurando-se a eles a confidencialidade das informações e o sigilo.

O projeto de pesquisa foi submetido ao Comitê de Ética na Pesquisa com Seres Humanos da Universidade Federal de Santa Catarina-UFSC (CEPSH/UFSC) e aprovado sob o certificado n51599315.6.0000.0121, em 18/02/2016. Foram, ainda, considerados todos os procedimentos éticos relacionados aos princípios de proteção dos direitos humanos, bem-estar e dignidade dos participantes.

Coerente com a psicologia histórico-cultural, a análise deste trabalho foi realizada com base nos núcleos de significação, conforme foram descritos por Aguiar e Ozella $(2006,2013)$. Essa técnica permite que se apreendam os sentidos do material qualitativo por meio da análise e organização de etapas, a saber: pré-indicadores, sistematização dos indicadores e sistematização dos núcleos de significação. Os resultados obtidos na análise seguem descritos, na próxima seção.

\section{Resultados e discussão}

As informações obtidas, referentes aos desafios no processo de escolarização dos estudantes, foram organizadas com base na articulação de diferentes indica- 
dores expressos pelos professores: a) Relação e parceria com a família; b) Características dos estudantes na atualidade; c) Complexidade da função do educador; d) Relação com a equipe pedagógica e com os colegas de trabalho; e) Judicialização das práticas escolares e direitos dos estudantes. Cada um desses indicadores segue detalhado na sequência deste trabalho.

\section{Indicador 1: Relação e parceria com a família}

A relação e a parceria dos profissionais da educação com a família são vivenciadas de forma complexa. Vigora um ideal de família nuclear, e a concepção da função da mulher é, ainda, limitada ao cuidado dos filhos. Muitos professores buscam a parceria com as famílias, porém nem toda parceria é bem-vinda. Pais que questionam os deveres escolares propostos pelos docentes ou participam de outros modos fora do esperado são vistos como desafios aos docentes, na realização do seu trabalho.

A ausência da família em relação ao processo educativo das crianças também é apontada. Os professores $^{1}$ responsabilizam e culpabilizam a família pela lacuna sentida e enfrentada no processo de escolarização das crianças, conforme o depoimento abaixo apresentado:

Eu ainda culpo, gente! A família. Eu sei que nós temos, e até podemos ter uma parcela ou outra de culpa, mas, pra mim, é a família. Se é separada, se cria sozinho. Se o pai é quem cria. Se é uma avó. [...] Se botou no mundo, se comprometa. Alguém tem que se comprometer (Ana).

Percebe-se, no depoimento, certa generalização no que se refere à explicação do fracasso escolar como relacionada à falta do comprometimento das famílias. Vale destacar que, segundo Fevorini e Lomâco (2009), a participação das famílias na escola não é fator determinante do sucesso escolar do filho. Essa informação corrobora os estudos pioneiros de Mello (1985), quando realizou uma pesquisa para entender as justificativas para o fracasso escolar dos estudantes. Ademais, os relatos dos docentes evidenciaram que eles pareciam não perceber a sua influência no processo, não identificando na escola ou nas condições sociais fatores para o insucesso escolar. Desse modo, as falas dos professores do grupo focal realizado ratificam as informações expostas na pesquisa de Mello (1985), uma vez que compreendem e significam os desafios na aprendizagem dos estudantes como dependentes das capacidades e potencialidades do próprio discente, vendo, na participação da família, a única explicação para a não efetivação da aprendizagem do estudante.

A fala dos educadores reflete que a participação dos pais (que vêm à instituição, comparecem a reuniões e acompanham os deveres dos filhos) é percebida quando satisfatória: "Olha! Os nossos melhores alunos são aqueles que os pais vêm na reunião. Aqueles que o pai ajuda. Aquela criança a gente vê que vai, entende?" (Ana). Conforme Ribeiro e Andrade (2006), a crítica dos agentes escolares em relação à participação dos pais na escola é recorrente, pois, para os educadores, os bons pais são aqueles que comparecem às reuniões. Contudo, para os autores citados, é necessário realizar uma reflexão mais aprofundada em relação à participação da família na escola, por meio da realização de um movimento sistemático de compreensão da realidade vivida pela família e pelo estudante. A escola necessita, dessa forma, rever a hierarquia do saber que estabelece com as famílias, pois muitas vezes procura as famílias para que estas complementem a função de escolarização, o que mantém uma relação instituída de poder que pouco agrega à efetivação da tão comentada parceria escola-família.

A participação da família na escola aparece associada diretamente à vida escolar dos filhos, conforme aponta a fala da professora Daiana, ao comentar: "Vou dizer o que eu acho. O que eu percebo. A questão dos pais. Têm aqueles que não participam da vida do filho, que não tão nem aí” (Daiana). No entanto, a participação dos pais na escola também é sentida como um mal-entendido ou risco (Rocha, 1996). Esse contexto é notório na fala de mais de um dos professores:

Então a preocupação dos pais não: é meu filho vai escrever de letra junta? Eles não vêm pra nós, perguntar: meu filho, por que não deixou meu filho brincar? Meu filho não pode comer tal lanche? Não vem perguntar, aonde eu, como pai, mãe, avó, tia, tio, alguém da família [...] posso ajudar na educação do meu filho ler? Pro meu filho ser um cidadão (Ana).

${ }^{1}$ Todos os nomes dos professores citados neste trabalho são fictícios, respeitando o sigilo, conforme proposto no Termo de Consentimento Livre e Esclarecido (TCLE), assinado por eles na realização do grupo focal. 
[...] Então, assim, oh! Eles vêm cobrar coisas. Eles não veem o que está escrito. Aí eles acham que tá errado. Porque assim [...] eu não vou dizer que eu não erro. A gente erra (Daiana).

Essas informações corroboram o estudo de Oliveira e Marinho-Araújo (2010), no qual destacam que a escola acusa a família de falta de participação e reclama do pouco retorno em relação à ajuda aos filhos. Contudo, quando essa participação acontece, muitas vezes, os professores se sentem invadidos, consideram que os pais não sabem participar, veem a participação como cobrança, ao invés de entenderem como uma possibilidade de ampliação do processo de ensino-aprendizagem (Oliveira, \& Marinho-Araújo, 2010).

Os professores também mencionam que sentem sua atuação profissional atrelada à avaliação dos pais. Para uma das professoras ouvidas, os "Professores não podem alterar a voz, porque têm pais reclamando" (Gabriela). Esse exemplo demonstra que os pais têm acompanhado a atuação dos docentes e que avaliam esse acompanhamento como uma forma de controle. A tensão mencionada está associada à complexificação do encontro entre os agentes escolares (Heckert, \& Rocha, 2012). Quando a família passa a participar mais da gestão da escola, ela também pode questionar posturas e práticas educativas dos educadores. Esse fato demonstra que a participação da família na escola é aceita sob determinados aspectos, pois, quando esta passa a avaliar a atuação do profissional, os docentes não veem tantos benefícios.

Percebe-se também, na fala dos professores, a tentativa de promover a educação dos estudantes, sendo que, para os docentes, as famílias não têm dado conta da transmissão cultural de mundo, considerada adequada por eles às crianças. Na fala de uma das entrevistadas do grupo focal, esse fato é evidenciado: "Mas o que eu vejo [...] tu fala com os pais e, no outro dia, continua igual. Não vejo a mudança. Da família, não tem um retorno. Falta um respaldo da família" (Ana).

Os pais são convocados para escutarem as queixas escolares de seus filhos, e a não efetivação das orientações é vista como uma falha das famílias, conforme mencionado na fala antes transcrita. Sabe-se que, para muitas famílias, a própria linguagem utilizada pela escola, a forma como ela entende que a família deve gerenciar suas funções, não faz sentido dentro do que acreditam ser sua função. Assim, ocorrem constantes embates entre os espaços familiar e escolar, com cobranças e desgastes que pouco contribuem para uma construção conjunta dos benefícios dessa parceria para a criança. Entende-se, desse modo, que pais e professores precisam ser estimulados a buscar, conjuntamente, soluções para as problemáticas enfrentadas, de modo a efetivarem soluções com ajuda mútua (Polonia, \& Dessen, 2005).

Na narrativa dos participantes do grupo focal, observou-se um compartilhamento da ideia de que o cuidado dos filhos é responsabilidade da família, mais especificamente da família nuclear - entendida como constituída por pai, mãe e filhos, vista como natural, imutável e universal, no decorrer dos séculos (Louro, \& Meyer, 1993). Essa percepção pode ser constatada na fala de uma das professoras: "a função de educar é da família, e a família é marido e esposa" (Elisa). Essa ideia reforça a compreensão cristalizada em relação à estrutura familiar, pouco se atentando às mudanças vivenciadas nas funções $\mathrm{e}$ papéis dos membros da família, no decorrer do tempo.

Entende-se que o professor é um formador de opinião, desse modo, sua postura e suas falas precisam ser embasadas e fundamentadas. Quando os professores enfrentam desafios no processo de escolarização e/ou no comportamento dos estudantes, por não localizarem um suposto "modelo tradicional de família”, acabam alimentando preconceitos em relação às configurações familiares. Na narrativa da professora Fernanda, a seguir, a grande dificuldade das famílias estaria relacionada à diversidade de configurações que se tem vivido atualmente: "Mas essa diversidade de famílias que está tendo hoje em dia, essa diversidade!" (Fernanda).

Porém, o sentido do suposto ideal de família tradicional é questionado por alguns dos integrantes do próprio grupo focal, haja vista que muitos dos participantes também provêm ou estão em configurações diversas:

Mas a minha família é diversificada. Eu me casei com 17. Eu tive meu filho com 22. [...] Me separei com 24. Fiquei com uma criança de 2 anos. Criei meu filho praticamente sozinha. E eu dava conta de trabalhar e estudar e dar conta dele. E hoje ele tá com 15 anos, lá no II ano. (Beatriz).

[...] Então os meus vão se matar, porque eu também sou separada! (Daiana).

Ah, ele é criado pela minha mãe, por isso ele é mimado. Não senhora! (Beatriz). 
Parece haver, na conversa entre os professores, uma mudança em relação ao sentido dado às configurações familiares. Quando os professores se percebem também implicados e refletem sobre isso, mudanças em relação às crenças sobre o tema emergem e fomentam novas possibilidades de pensar a configuração familiar como decorrente das próprias transformações que a sociedade vivencia, bem como dos novos papéis que vêm sendo assumidos pela mulher, ao longo dos anos. Essa análise, realizada no grupo, permite perceber esse espaço como um espaço de análise coletiva de práticas e conflitos cotidianos, e, também, um espaço de construção de possíveis novos encontros (Fernandes,Moura, Fernandes, Joca, \& Patriota, 2009).

Ainda é comum se encontrar, no discurso dos educadores, um olhar cristalizado em torno das funções materna e paterna, sendo o pai significado como responsável pelo sustento financeiro da casa, e à mãe caberia o papel de educadora dos filhos e a responsabilidade no acompanhamento das tarefas escolares, conforme apontam Fevorini e Lomâco (2009). Aquelas famílias que não se encaixam nesse modelo ideal são vistas como responsáveis pela disparidade escolar de seus filhos. Os próprios educadores trazem reflexões em relação à mulher e às funções que ela assumiu na sociedade atual, que a tem deixado mais "distante do cuidado dos filhos", atribuição que é predominantemente considerada como sua responsabilidade. Nas palavras da professora Beatriz, as mulheres "Fugiram da sua responsabilidade!". Já a professora Fernanda, a qual também considera a atribuição de acompanhar a vida escolar dos filhos como uma função da mulher, destaca que, em decorrência das demandas atuais, “Tem mãe que há falha né! [...]. Mas nós vivemos numa sociedade capitalista. E a questão capitalista, a mulher tanto perdeu quanto ganhou, né?" (Fernanda).

Percebe-se que, apesar de todas as conquistas das mulheres na sociedade, ainda vigoram limitações em relação as suas competências, como se unicamente a elas fosse incumbido o papel de cuidado dos filhos. A característica de cuidadora dos filhos, atribuída às mulheres, denota a construção histórica relacionada ao feminino. Compreende-se por papel os "padrões ou regras arbitrárias que uma sociedade estabelece para seus membros e que definem seus comportamentos, suas roupas, seus modos de se relacionar ou de se portar" (Louro, 1997, p. 24). Desse modo, há uma apreensão, pelos professores, do significado de que a responsabilidade pelos cuidados dos filhos cabe, exclusivamente, às mulheres, sendo que, quando isso não ocorre, é considerado inadequado.

Salienta-se que outros cuidadores com igual importância em relação à parentalidade são pouco citados, apontando para a necessidade de se desconstruir, junto aos participantes do grupo focal, os binarismos de sexo/gênero, conforme propõem Gesser et al. (2015), que aparecem de forma naturalizada em suas falas. Assim, poder-se-á corroborar a construção de processos educativos comprometidos com a promoção da igualdade de gênero, no contexto escolar.

Observa-se, desse modo, a amplitude dos sentidos dados à participação e parceria da família, neste indicador. São constantes as falas dos professores que mencionam a não participação e a responsabilização das famílias no acompanhamento das atividades escolares dos filhos. Porém, percebe-se que nem toda participação da família é acolhida. Famílias que questionam ou buscam seus filhos em horários fora do considerado adequado são vistas como risco. As próprias crenças em relação à família ideal, às configurações familiares e ao papel da mulher/mãe parecem ser pensadas pelos educadores com base num modelo tradicional de família que vem sendo refletido, no contexto de mudanças vivenciadas na sociedade atual. Desse modo, entende-se que esse indicador fomenta questionamentos e reflexões em relação ao papel da escola, dos educadores, tanto quanto da formação repassada aos estudantes, uma vez que algumas reflexões dos docentes vêm permeadas de conceitos que limitam o olhar para a diversidade da vida humana e as singularidades dos sujeitos.

\section{Indicador 2: Características dos estudantes na atualidade}

Em relação às características dos estudantes, os docentes comentam sobre a falta de atenção deles na escola. Dizem também que comportamentos de brincadeira são muito presentes e que atrapalham o andamento da aula. Chama a atenção dos docentes, ainda, os comportamentos "destoantes do gênero dos estudantes", que acabam não refletidos, reproduzindo a lógica heteronormativa.

Para alguns dos professores ouvidos, os estudantes parecem pouco interessados em escutar, quando eles chamam atenção sobre suas características, conforme se observa na fala da professora: 
"A gente chama a atenção deles e eles param num momento, eles escutam. Choram, ficam tristes, deprimidos. Não dá dois, cinco minutos volta tudo novamente" (Beatriz).

Considera-se que a falta de atenção, apontada pela professora Beatriz, pode ser decorrente de inúmeros motivos. Moysés e Collares (2014) fazem refletir em torno da não atenção das crianças em sala de aula, ressaltando que toda criança que não presta atenção está atenta a outra coisa. Não há possibilidade de as crianças não estarem atentas a algo. Porém, esse algo pode ser um objeto diferente daquele que o adulto considera relevante.

Em uma de suas pesquisas, Stelko-Pereira, Valle e Williams (2015) identificaram que os estudantes tendem a ter mais atenção e demonstrarem maior interesse nas atividades escolares que tenham utilidade ou se relacionem ao seu dia a dia, com materiais didáticos e ensino adequado às suas necessidades e que, de fato, eles se sintam estimulados. Desse modo, contextualizar a falta de atenção em sala de aula é fundamental para se pensar, de maneira mais ampliada, o que ela pode representar.

Do mesmo modo, os comportamentos de brincadeiras são mencionados pelos educadores como constantes em sala de aula e são considerados preocupantes para a efetivação da aprendizagem. Segundo uma das professoras ouvidas: "Então eu digo assim: Meu Deus do céu! O que não entra na cabeça das crianças que é brincadeira? É brincadeira. Temos alunos novos, alunos que são repetentes, que eu estou preocupada mais ainda" (Fernanda). Entende-se que o brincar tem uma função importante para o próprio desenvolvimento infantil (Marques, \& Sperb, 2012). Para Vygotsky (1991), o brincar representa a criação da zona de desenvolvimento proximal que impulsiona a criança para além do estágio de desenvolvimento que ela já atingiu. Pesquisas mostram que a brincadeira possibilita a elaboração da agressividade e o controle da angústia por parte da criança, em seus contatos sociais (Friedmann, 1996; Maluf, 2003). Assim, no contexto citado, é importante compreender as brincadeiras dos estudantes e o que elas podem estar expressando, haja vista muitos estudantes estarem iniciando sua inserção no ensino regular - contexto diferente daqueles em que estavam, antes da escola.

No olhar de Masini (2013), as crianças têm "dado trabalho em sala de aula". Porém, o sentido de dar trabalho precisa ser amplificado, pois varia de criança para criança e implica tanto na forma como a família como também a escola se relacionam com elas. Desse modo, o estar junto com as crianças e acolher suas necessidades é essencial para não quantificar e patologizar seus comportamentos.

Outra questão identificada na pesquisa foi que os professores parecem cada vez mais impressionados com as características consideradas "destoantes" do gênero da criança. Percebe-se, na fala dos educadores, uma naturalização em relação a como meninos e meninas "devem" se comportar, conforme fala da professora Beatriz: "Hoje eu estava subindo aqui pela rampa, e aí uma menina foi e ela foi xingando três meninos daqui de baixo até lá em cima na rampa. Uma menina! Ela dizia assim: 'vem, vem que eu te como na porrada'” (Beatriz).

Pode-se analisar o estranhamento da professora Beatriz à luz dos estudos de gênero. Há um processo de naturalização de lugares sociais atribuídos à masculinidade e à feminilidade. Aos meninos, são incentivados e esperados comportamentos mais ativos. Às meninas, são ensinados os comportamentos mais dóceis e passivos. Considera-se importante apontar que a masculinidade e a feminilidade são construções histórico-culturais marcadas num tempo e espaço, o que justifica que tanto meninos como meninas possam manifestar agressividade de formas variadas (Lisboa, \& Koller, 2001). Louro (2011) aborda que o sujeito aprende a ser do gênero masculino ou feminino, homossexual ou bissexual por meio de comportamentos aprendidos na família, escola, cinema, televisão, dentre outros. São as pedagogias culturais que constituem o gênero e a sexualidade. A fala da professora Beatriz, anteriormente transcrita, reproduz a naturalização do gênero feminino como limitado a um determinado padrão de comportamento, o que pode dificultar o reconhecimento da diferença, na nossa sociedade, uma vez que se percebe operando a lógica da heteronormatividade. Nesse sentido, Louro (2011) ressalta que a escola tem uma importante função social, que é a de contribuir com a desconstrução da lógica heteronormativa.

Alguns professores do grupo focal acreditam que muitas das características dos estudantes, em sala de aula, podem estar associadas à própria dinâmica da aula, que não fomenta o interesse dos estudantes, conforme aponta o depoimento da professora Beatriz: "Eu estou dizendo que tem os dois extremos. Têm 
aqueles que incomodam porque não sabem, mas têm aqueles que incomodam porque estão além" (Beatriz).

Olhar para o que representa um modo de estar na escola de um estudante é ampliar o contexto de sua compreensão. Quando a professora Beatriz reflete que o estudante pode estar tumultuando em sala de aula, pois já sabe o conteúdo, isso representa uma compreensão diferenciada, que possibilita entender o sujeito em sua singularidade. Essa percepção corrobora o que conclui Amaral (2000, p. 138), quando aponta que também há falta de habilidade em "demonstrar ao aluno a necessidade e a utilidade do que está sendo exposto e a pouca e rara preocupação em organizar as atividades didáticas de forma mais articulada e dinâmica podem, [...] explicar o desinteresse e a falta de atenção do aluno". Desse modo, o trabalho voltado à articulação entre teoria e prática, bem como à consideração das diferenças no contexto de sala de aula, refere-se a um processo desafiador e reflexivo, pois desloca o olhar do suposto "estudante ideal" aprendido na formação inicial de professores.

Assim, este indicador apontou que os sentidos atribuídos pelos docentes à forma como os estudantes se comportam estão relacionados aos significados historicamente produzidos sobre o que é caracterizado como um estudante normal. Bagliere et al. (2011) destacam a necessidade de desconstruir todas as normas que produzem os desvios e processos de exclusão dos estudantes. $\mathrm{Ou}$ seja, é necessário questionar normas relacionadas a questões étnico-raciais, deficiência, classe social, gênero, sexualidade e demais diversidades para dessa forma promover uma educação inclusiva de todas as diferenças (Gesser et al., 2015). Compreende-se que refletir criticamente sobre o processo de homogeneização dos estudantes e suas implicações pode contribuir para a construção de processos educativos inclusivos na escola.

\section{Indicador 3: Complexidade da função do educador}

As informações obtidas na pesquisa evidenciaram que há uma predominância na compreensão da função social do professor como restrita à transmissão do conhecimento historicamente produzido. Assim, os participantes do grupo focal, na sua quase totalidade, criticaram a demanda atual de terem de acolher e orientar os estudantes em aspectos que não estão relacionados à transmissão do conhecimento.

Um dos professores apresenta, na sua visão, qual deveria ser o papel do professor no contexto da sala de aula: "Nosso papel seria mediar o conhecimento do aluno. [...] O nosso papel não é educar as crianças, é escolarizar" (Hugo).

Nesse sentido, é importante salientar que tal maneira de pensar a educação formal é herança da constituição da organização escolar e da pedagogização do conhecimento. Para Varela (1994), a autoridade do mestre jesuíta e os saberes ditos verdadeiros, repassados aos estudantes, expropriaram historicamente os saberes trazidos pelas crianças. Os reflexos disso são vivenciados, atualmente, no cotidiano dos estudantes que são vistos como sujeitos destituídos de uma história anterior à da aprendizagem que ocorre no contexto escolar. Porém esse tipo de organização e hierarquia de saber não atingiu o objetivo proposto, uma vez que ocorreram resistências dos estudantes aos saberes a que são submetidos. Todo esse contexto está presente na fala do professor Hugo, antes mencionado, uma vez que ele entende sua função como relacionada apenas à transmissão de conteúdos formais e ao desenvolvimento da capacidade cognitiva dos estudantes.

A desvinculação entre aprendizagem e afetividade, no contexto escolar, é observada na fala da professora Ana, quando diz: "a gente é médica, a gente é enfermeira, a gente é mãe, a gente é psicólogo, e, muitas vezes, a gente não faz o nosso principal papel: de professor" (Ana). Desse modo, realizar papéis variados em função do contato diário com os estudantes e com a organização escolar vem sendo uma prática recorrente e necessária por parte dos educadores. Isto é, entende-se que o estudante, no contexto escolar, relaciona-se de forma inteira, intelectual e emocionalmente.

Os professores também não se percebem como responsáveis pelos cuidados, o que pode ser também decorrente de a escola não ter uma equipe que consiga dar suporte em questões relacionadas à saúde e a aspectos psicossociais vivenciados pelos estudantes. Nesse sentido, alguns educadores, ao perceberem como seu trabalho tem se organizado, mencionam as diversas responsabilidades que dizem precisar assumir, reconhecendo essas atribuições como dificuldades em seu trabalho de educador. Na narrativa seguinte, isso fica evidente: 
Pera, só para justificar a nossa dificuldade, né? Dificuldade em sala. Médico é médico. Ele não pode ser médico e dentista. Dentista é dentista, ele não pode ser cirurgião plástico. Nós professores temos que ser pai, mãe, periquito, papagaio. Tem que ser, machucou, pronto, você tem que fazer os primeiros socorros (Hugo).

É importante destacar que a dissociação entre a transmissão do conhecimento e as demais funções da educação e do cuidado, apontada nos depoimentos acima, é cada vez mais presente na educação básica e no ensino superior. Tal entendimento está em desacordo com as noções contemporâneas de educação inclusiva, as quais têm sinalizado a importância de os professores buscarem, nos processos educativos, as relações de interdependência e o acolhimento das diferenças (Baglieri et al., 2011). Autores vinculados aos estudos sobre deficiência têm criticado fortemente essa perspectiva que cinde o cuidar e o educar, uma vez que ela, sob a égide de um suposto mito da independência (Kittay, Jennings \& Wasunna, 2005), obstaculiza que crianças com deficiência ou com alguma diferença cultural ou linguística possam ser incluídas no contexto educacional em igualdade de condições. Todavia, os depoimentos dos professores e o sofrimento que emana das suas falas evidenciam que eles não estão preparados para atenderem as várias demandas a que são apresentados diariamente, além do ensino formal.

Salienta-se, também, que embora houvesse o predomínio de uma concepção de educação vinculada à transmissão do conhecimento, também os professores evidenciaram, no grupo focal realizado, uma compreensão mais ampliada do exercício de sua função. Essa pode ser identificada na fala da professora Indianara:

Mas esse é nosso papel como educador! Quando eu vejo uma criança mal-educada, até do meu vizinho. [...] Eu vejo aquele evento e não é porque sou professora. É meu dever ético. Eu acho que eu escolhi ser professora porque era uma das coisas que eu fazia naturalmente, não que eu queria ganhar dinheiro com isso, mas era uma coisa como trabalho.

A fala da professora Indianara corrobora as análises de Mattos,Pérez, Almada, e Castro (2013), quando esses autores comentam que a relação entre profes- sores e estudantes é atravessada não só pelas trocas de conhecimento, mas também pelo afeto e cuidado. Para muitas crianças, a escola representa o principal espaço de sociabilização de suas vidas e convivência com as diferenças. Dessa maneira, os vínculos estabelecidos na escola e a promoção do cuidado também são tarefas que possibilitam aos estudantes e professores mutualidade nas relações estabelecidas. Esse fato contribui para pensar os lugares dos estudantes e professores como relacionais, que se constituem nas interações estabelecidas, marcados pelas condições materiais e contextuais.

Assim, os sentidos dados pelos professores às atribuições que exercem revelam seu modo de ser e agir, no espaço escolar. No grupo ouvido, os professores atribuem sentidos amplos em relação a sua função diária, indo desde "pensarem que realizaram mais funções do que seria seu papel” (Ana) até pensar que a "função de educador é constitutivo de sua subjetividade, podendo perpassar o contexto da sala de aula" (Indianara). Entretanto, suas percepções em relação à função que assumem como educadores se apresentam limitadas a uma concepção de educação que, por muito tempo, tentou abranger somente o desenvolvimento cognitivo dos estudantes. No entanto, a relação com os estudantes vem demonstrando que o trabalho a ser concretizado pelos educadores precisa se atentar para a esfera das emoções, do cuidado e da percepção daqueles em sua integralidade.

\section{Indicador 4: Relação com a equipe pedagógica e com os colegas de trabalho}

Os professores de anos iniciais possuem um papel fundamental na formação dos estudantes, uma vez que medeiam o ensino da leitura, da escrita, do contar (Lima, 2012). Dessa forma, sua atuação em sala de aula é ampla, pois precisam estar preparados para ensinar diversos conhecimentos, possibilitando aprendizagens consistentes. Para desenvolver seu trabalho, o docente necessita de suporte e ajuda da equipe escolar, o que pode contribuir para a construção conjunta de estratégias de ensino voltadas à promoção do sucesso escolar, bem como para evitar o sentimento de isolamento e solidão que muitos professores vivenciam no cotidiano da escola.

Nesse sentido, os depoimentos dos professores mostraram que eles têm a expectativa de que a coordenação pedagógica encaminhe as situações identificadas por eles como desafiadoras, no processo de escolariza- 
ção dos estudantes de forma resolutiva, não se percebendo como participantes na construção dessas estratégias. Além disso, em algumas situações os professores têm uma desconfiança em relação às ações implementadas pela coordenação pedagógica. O depoimento do professor Hugo é representativo desta situação:

Desde o ano passado [...] nós estamos sozinhos dentro da sala de aula. A supervisão não funciona, a orientação não funciona. Leva lá para fazer desenho [referindo-se ao que os estudantes fazem ao irem para direção da escola] não sei mais quantas. [...] Volta pior. E, ainda ele olha pra tua cara, "pode mandar eu vou para lá fazer desenho mesmo. Lá é melhor do que ficar na tua sala" [...] Quando vocês falam assim, nós chamamos a mãe. [...]. Mas será que realmente é chamada a mãe? Das vezes que a mãe é chamada. Às vezes é chamada e atendida às escondidas, como você nem sabe que a mãe veio.

Portanto, percebe-se uma fragmentação na relação professor (sala de aula) e direção-supervisão da escola. Os professores sentem que podem contar muito pouco com essa rede de apoio, desenvolvendo seu trabalho cada vez mais sozinhos. Louro (2008) destaca que as dificuldades experimentadas na relação com colegas de trabalho - como os da equipe pedagógica - podem fragilizar a identidade docente, afetando seu envolvimento com a profissão e com o trabalho. Na fala transcrita a seguir, parece haver uma síntese de como a relação com a equipe pedagógica acontece: "A gente vai ter uma reunião pedagógica no final que eu até já sei como é que é. Como foi o teu ano, obrigada, tchau, quem sabe ano que vem a gente se vê. Ah, você tem problema com o aluno, até dezembro a gente dá conta (Hugo)".

Essa fala corrobora o apontado por Gasparini, Barreto e Assunção (2005, p. 191), quando relatam que "a administração escolar não fornece os meios pedagógicos necessários à realização das tarefas, cada vez mais complexas". Entende-se, desse modo, que há um distanciamento entre as reais necessidades dos professores e o trabalho desenvolvido pela equipe pedagógica. Ou seja, o diálogo é escasso, há poucas paradas pedagógicas, são raros os momentos de conversação em grupo. Esse cenário traz reflexos também para as relações entre os próprios educadores, uma vez que parece haver necessidade de maior alinhamento em relação aos objetivos do trabalho na instituição.
Entende-se que a parceria e as trocas entre os sujeitos devem ser valorizadas e incentivadas, uma vez que resultam na experiência humana de conhecimento coconstruído com o outro (Raposo, \& Maciel, 2005). Dessa maneira, os professores necessitam de apoio em suas ações, com suporte às necessidades que são apresentadas no dia a dia da sala de aula. Essas interações, certamente, proporcionarão novos conhecimentos e novas estratégias para a resolução dos problemas enfrentados diariamente.

Observa-se que a própria parceria entre os colegas de trabalho se apresenta frágil, conforme colocado por uma das professoras do grupo focal: "Acho que tem uma crítica que está sendo discutida que não é verdade. Porque assim, oh, pra ajudar não tem ninguém" (Fernanda). Raposo e Maciel (2005) analisam que as dificuldades de relação entre os docentes se refletem na cultura da organização escolar que pode ser presente entre professores da mesma série ou área. Esse fato influencia nos resultados educacionais que acabam ficando muito aquém do potencial de realização.

Durante o grupo focal, uma das docentes propôs que os professores presentes buscassem a diretora da escola para conversar sobre os desafios por eles enfrentados diariamente na instituição. Pensando em relação à importância da união da categoria profissional dos professores, aconteceu o seguinte diálogo entre os docentes: "A união, a nossa união [...] Por isso que eu estou pedindo para vocês, já que estão todos aqui. (Ana) Uma parada pedagógica. (Elisa)/Não foi parado. (Beatriz)Então não adianta, vai continuar a mesma coisa" (Liana).

Esse momento de troca do grupo é rico e potencializa a todos pensarem sobre a implicação que possuem na execução do seu trabalho na instituição. Conforme Mariano e Muniz (2006), "as relações com outros trabalhadores que sofrem [...] impulsiona na construção de estratégias defensivas em comum". No grupo focal realizado, os professores reconhecem que eles têm possibilidades de avaliar o trabalho e pensar estratégias para aquilo que não vem dando certo. A fala de uma das professoras é enfática, ao apontar que os professores também têm sua responsabilidade na garantia do processo de aprendizagem dos estudantes: "Mas esse 220 volts que a gente tá trabalhando a culpada quem é? Não são os pais, somos nós" (Liana). A professora Liana também chama atenção para a importância do olhar para si, para o seu fazer profissional: 
A crítica não vai adiantar nada. [...]. Porque profissional e falta de ética a gente não pode ter. [...] a gente é um profissional e a gente tem que agir profissionalmente. [...]. Assim, oh, em relação a chamar a direção, a gente tem ir e dizer: Oh! A gente tá precisando disso, vamos tentar mudar isso? (Liana).

Os professores que tomam a frente na busca de alternativas se sentem sozinhos e visados pela direção, pois são os protagonistas das reivindicações do grupo. Na fala de uma das educadoras, isso é apontado: "Sabe o que que acontece? A gente pede, mostra as nossas angústias. Um monte de gente fala no corredor. Um monte de gente troca figurinha com as amigas. Chega na reunião é pum [referindo-se ao ficar quieto dos colegas na reunião]" (Ana).

Sawaia (2002) é uma autora que, com base em uma perspectiva ético-política inspirada principalmente em Vygotsky e Espinosa, aponta a importância da participação social em espaços dialógicos para a potencialização de grupos. Com base em suas reflexões, pode-se afirmar que a promoção de espaços voltados ao diálogo e à construção conjunta de estratégias pedagógicas entre os professores e equipe pedagógica pode contribuir para a construção de processos educativos inclusivos e voltados à superação do fracasso escolar. A autora reflete em relação à participação e ao fomento da potência de ação no sujeito, pois este passa da passividade à atividade. Quando afetado, o sujeito consegue se perceber como responsável pelas suas atitudes, buscando potencializar bons encontros. Segundo a autora, a participação "cura a servidão" em temporalidades e espacialidades diferentes. Desse modo, na fala, antes transcrita, dos professores, muitos parecem não conseguir alimentar bons encontros com o grupo, ou não se afetando mutuamente ou se envolvendo em movimentos com objetivos comuns.

Passos (2001) reflete sobre a importância da interação entre os pares, expondo que ela precisa ser valorizada, e os professores podem se apoiar mutuamente, sustentando o crescimento um do outro, olhando para as dificuldades e compreendendo as relações que estão envolvidas no contexto escolar. Conforme Raposo e Maciel (2005), nas escolas onde se consegue construir um bom nível de relações sociais, acontece a potencialização dos resultados educacionais, refletindo-se no desenvolvimento dos trabalhos tanto individuais como coletivos. Dessa maneira, o professor precisa compreender que seu espaço de trabalho também é um espaço de resolução dos desafios enfrentados. A parceria (equipe pedagógica e colegas de trabalho) é fundamental para buscar novas estratégias para o melhoramento do processo de escolarização dos estudantes, bem como para favorecer as interações interpessoais nesse espaço.

Destaca-se que os sentidos atribuídos à relação com os colegas de trabalho e à equipe pedagógica da escola denotam distanciamento e falta de apoio, que se refletem no processo de escolarização dos estudantes. Os professores ficam sozinhos em suas buscas, demonstrando, nesse contexto, pouco conseguir se articular para encontrar novas alternativas de trabalho junto à coordenação da escola. E, ainda, na fala dos docentes, nota-se o pouco preparo destes em mediar os conflitos em sala de aula, recorrendo às instâncias de direção e coordenação pedagógica. Percebe-se, também, a ausência de retorno da coordenação pedagógica que, quando solicitada, parece fazer seu trabalho de maneira restrita à participação do educador. Esse cenário da instituição pode contribuir para os sentimentos de isolamento dos docentes, de desmotivação em relação à carreira e de pouca confiança em relação à execução do trabalho.

\section{Indicador 5: Judicialização das práticas escolares e direitos dos estudantes}

Desde os anos 1990, profundas mudanças foram presenciadas no cenário da educação. A busca pela universalização do ensino constituiu-se numa tentativa de assegurar o acesso e a permanência dos estudantes na escola (Heckert, \& Rocha, 2012). Leis e programas foram criados com o intuito de garantir a proteção integral da infância, com base na ideia da criança como cidadã e portadora de direitos.

Muitos professores avaliam os avanços legais relativos à universalização da educação com ressalvas. Uma das professoras participantes do grupo focal relata como sente, especificamente, a implantação do Estatuto da Criança e do Adolescente (ECA):

O processo da escola também não pode ser tão rígida também em função do estatuto da criança e do adolescente. Tudo cobre, tem certas coisas que a gente não pode agir. Porque o pai vai no ministério público. E estoura na escola. A escola tem que responder a processo. É juiz, não, tu não pode negar vaga para tal aluno (Elisa). 
Percebe-se, desse modo, a judicialização das práticas escolares, com a expansão das ações da justiça no território da escola, para assegurar deveres não cumpridos em detrimento de direitos sociais (Heckert, \& Rocha, 2012). Salienta-se necessário, aqui, mencionar que se entende judicialização como "o movimento de regulação normativa e legal do viver, do qual os sujeitos se apropriam para a resolução dos conflitos, reproduzindo uns com os outros o controle, o julgamento e a punição das condutas" (Oliveira, \& Brito, 2013, p. 79). Identificou-se, portanto, que alguns professores avaliam a ampliação de direitos das crianças e adolescentes e a judicialização das práticas escolares como negativos. Essa avaliação parece estar relacionada à dificuldade que esses participantes têm de estabelecer relações dialógicas e voltadas à resolução de conflitos com os demais atores sociais da escola, especialmente com os estudantes e familiares.

Os docentes também problematizaram sobre projetos de não reprovação escolar dos estudantes. Os discentes são aprovados automaticamente até a terceira série do ensino fundamental, não podendo ser retidos em caso de aproveitamento insuficiente. Nesse sentido, Facci (2010) chama atenção para o fato de que muitos estudantes não têm conhecimento suficiente para passar para o próximo ano e vagam pela escola sem receber o socorro em relação às suas necessidades de aprendizagem. Desse modo, essa passagem de ano gera efeitos difíceis de serem trabalhados, quando esse estudante já avançou anos no processo educativo. Esse incômodo é referido por uma das docentes:

Assim, a minha maior angústia assim, que eu estava bem estressada, é assim: por conta dessa regra de que não pode reprovar, no quarto ano tem muita criança que não é da escola, mas tá comigo. Gente estava me sentindo uma fraude [...] Tá, porque eu disse assim, se aquele aluno é uma criança que tá perdendo o tempo, tá tirando nota dois, três, a gente vai atrás dele, não sem essa preocupação de educar. No final, ele vai passar. E passou o ano todo com a professora dizendo que ele não ia passar [...]. Oh, eu estou participando dessa fraude (Indianara).

Salienta-se que a política educacional mencionada faz parte de uma tentativa nacional de redemocratização da educação. Desse modo, tais políticas se configuraram como desafios permanentes para os professores em relação ao processo educacional, uma vez que eles ficam de "mãos atadas", quando percebem que os estudantes não atingiram a aprendizagem suficiente para passar ao próximo ano. Assim, o grande desafio se pauta em como garantir que o estudante dos anos iniciais adquira os conhecimentos necessários para avançar para as fases seguintes do ensino.

É importante destacar que todas as mudanças geradas no processo educativo da educação pública não foram acompanhadas de ajustes na formação de professores para atender ao público presente no espaço escolar. A fragilidade na formação inicial e continuada dos docentes repercute no descompasso entre as necessidades dos estudantes e as possibilidades dos próprios professores que estão nesse contexto. Considera-se que as dificuldades apresentadas pelos professores que participaram do grupo focal refletem, também, as mudanças vividas no contexto educativo, bem como a formação insuficiente que receberam das instituições formadoras (Davis, Nunes, Almeida, Silva, \& Souza, 2011).

Pode-se dizer que esse indicador aponta para os sentidos referenciados pelos professores em relação às legislações de proteção à infância e aos programas que visam a assegurar direitos às crianças em idade escolar. Os docentes compreendem as mudanças nas políticas educacionais e a relação com o direito como limitantes a sua atuação profissional. As mudanças apontadas refletem no cotidiano dos educadores que veem suas práticas sendo atravessadas por agentes externos, limitando o diálogo e a busca de soluções conjuntas com a família. Isso tudo demonstra que os desafios no processo ensino-aprendizagem são amplos e precisam ser pensados pelos agentes escolares com abertura à parceria da família, diminuindo a interferência de outros agentes - por exemplo, o direito - que não convivem com a realidade escolar.

\section{Considerações finais}

O objetivo deste artigo foi compreender, com os professores, os sentidos atribuídos aos desafios no processo de escolarização, nos anos iniciais do ensino fundamental de uma escola pública. As informações obtidas no estudo evidenciaram que esses desafios estão relacionados às expectativas que os professores criam sobre os estudantes e suas famílias, sendo estas ancoradas em um ideal de estudante e num modelo de família nuclear, cuja mulher ainda é vista como a única 
cuidadora e responsável pelos filhos. Desse modo, o pai e outros cuidadores com igual importância não são comentados pelos educadores. Destaca-se que esta ideia apresentada se refere a uma preocupação, uma vez que esses professores são formadores de opinião bem como transmissores de conhecimento aos estudantes. Salienta-se que, ampliar concepções, desconstruir paradigmas, repensar novos jeitos de ser e estar e acolher as diferenças são aspectos relevantes que precisam compor a formação e o exercício do papel docente. Quando suas concepções são fundadas em crenças, conforme o identificado, pouco se avança em termos da construção de uma sociedade mais crítica e ciente de sua história e respeito às diferenças humanas.

O estudo mostrou que a escola não tem conseguido fornecer espaços de escuta e acolhimento para os docentes que sentem sua função social como complexa e desafiadora, diante do processo de judicialização das práticas escolares por eles vivenciado. A relação entre a equipe pedagógica e os docentes, nessa instituição, é indicada como distante. Professores acabam sozinhos nas salas de aula, dando conta das demandas apresentadas. Ao buscarem auxílio da escola, esta acaba sendo pontual (como colocar o estudante identificado com problemas para desenhar) e/ou descontínua quando a escola chama os pais da criança e não convida os professores para essa conversa. Entende-se que a valorização da participação da família na escola começa por esses momentos, em que também se valorizam as contribuições de todos (pais, professores, coordenação) no intuito de chegarem à melhor solução para as dificuldades vivenciadas pelo professor na sua relação com o estudante, seja de ordem acadêmica ou relacional.

A pesquisa também apontou que os desafios relacionados à formação docente e à própria organização da política educacional foram pouco mencionados, durante o grupo focal. Isso chamou a atenção, uma vez que os efeitos desses fatores influenciam diretamente na atuação do professor. Entende-se que o investimento em políticas educativas é fundamental para as melhorias necessárias à atuação profissional assim como para o exercício mais atualizado da profissão por meio de formações e cursos que esses profissionais necessitam fazer para atender às demandas cotidianas. Desse modo, possibilitar aos docentes espaços para pensar seu papel profissional e os impactos da política neoliberal em relação ao seu atuar são possibilidades de apropriação dos educadores da história que envolve a profissão e dos percalços vivenciados nas últimas décadas.

Por fim, considera-se fundamental - com base no exposto - refletir sobre a importância do trabalho do psicólogo no contexto educativo, tendo como foco a desconstrução dos modelos idealizados de estudante e família. A promoção de espaços de escuta e acolhimento aos docentes também pode ser uma eficiente estratégia para a promoção de relações sociais mais potencializadoras, no contexto escolar. Assim, faz-se necessário problematizar a organização da política educacional e os seus efeitos na educação. Acredita-se que essa atuação possa gerar novos deslocamentos e entendimentos relacionados à prática docente.

\section{Referências}

Aguiar,W.M.J.,\&Ozella,S. (2013).Núcleosdesignificação:Aprimorandoapropostadosnúcleos designificação. Revista Brasileira de Estudos Pedagógicos, 94 (236), 299-322. https://doi.org/10.1590/S2176-66812013000100015

Aguiar, W. M. J., \& Ozella, S. (2006). Núcleos de significação como instrumento para apreensão da constituição dos sentidos. Psicologia: Ciência e Profissão,26(2), 222-245. https://doi.org/10.1590/S1414-98932006000200006

Amaral, C. M. T. (2000).A (in)disciplina em sala de aula: O papel do professor. Acta Scientiarum, 22(1), 135-140.

Baglieri, S. B. L. M., Beijoan, L. M., Broderick, A. A., Connor, D. J., \& Valle, J. (2011). [Re]claiming "inclusive education" toward cohesion in educational reform: Disability studies unravels the myth of the normal child. Teachers College Record, 113(10), 2122-2154.

Camargo, D. (2004). As emoções e a escola. Curitiba, PR: Travessa.

Carlini-Cotrim, B. (1996). Potencialidades da técnica qualitativa grupo focal em investigações sobre abuso de substâncias. Revista de Saúde Pública, 30(3), 285-293. https://doi.org/10.1590/S0034-89101996000300013

Carvalho, M. F. (2013). O aluno com deficiência intelectual na escola: Ensino, aprendizagem e desenvolvimento humano. In S. M. F. Meletti, \& M. C. M. Kassar (Org), Escolarização de alunos com deficiências: Desafios e possibilidades (pp. 172-203). Campinas, SP: Mercado de Letras. 
Davis, C., Nunes, M., Almeida, P. C. A., Silva, A. P. F., \& Souza, J. C. (2011). Formação continuada de professores: Uma análise das modalidades e das práticas em estados e municípios brasileiros (Coleção Textos FCC, 34). São Paulo, SP: Fundação Carlos Chagas.

Dias, M. A. H., Pereira, M. M. B., \& Borsel, J. V. (2013). Avaliação do conhecimento sobre a discalculia entre educadores. Audiology: Communication Research, 18(2), 93-100. https://doi.org/10.1590/S2317-64312013000200007

Facci, M. G. D. (2010). A escola é para poucos? A positividade da escola no desenvolvimento psicológico dos alunos em uma visão Vygotskyana. Revista Psicologia Política, 10(20), 315-328.

Fantacini, R. A. F., \& Dias, T. R. S. (2015). Professores do atendimento educacional especializado e a organização do ensino para o aluno com deficiência intelectual. Revista Brasileira de Educação Especial, 21(1), 57-74. https://doi.org/10.1590/S1413-65382115000100005

Fernandes, A. M. D., Moura, A. M. A., Fernandes, D. J., Joca, E. C., \& Patriota, G. F. R. (2009). Psicologia, educação e análise institucional: Perspectivas no campo da formação de educadores. RevistaAletheia, (29), 204-216.

Fevorini, L. B., \& Lomônaco, F. B. (2009). O envolvimento da família na educação escolar dos filhos: Um estudo exploratório com pais das camadas médias. Psicologia da Educação, (28), 73-89.

Friedmann, A. (1996). Brincar, crescer e aprender: O resgate do jogo infantil. São Paulo, SP: Moderna.

Gasparini, S. M., Barreto, S. M., \& Assunção, A. A. (2005). O professor, as condições de trabalho e os efeitos sobre sua saúde. Revista Educação e Pesquisa, 31(2), 189-199. https://doi.org/10.1590/S1517-97022005000200003

Gesser, M., Oltramari, L. C., Cord, D., \& Nuernberg, A. H. (2012). Psicologia escolar e formação continuada de professores em gênero e sexualidade. Psicologia Escolar e Educacional,16(2), 229-236. https://doi.org/10.1590/S1413-85572012000200005

Gesser, M., Oltramari, L. C., \& Panisson, G. (2015). Docência e concepções de sexualidade na educação básica. Psicologia \& Sociedade, 27(3), 558-568. https://doi.org/10.1590/1807-03102015v27n3p558

Heckert, A. L. C., \& Rocha, M. L. (2012). A maquinaria escolar e os processos de regulamentação da vida. Revista Psicologia \& Sociedade, 24(esp), 85-93. https:// doi.org/10.1590/S0102-71822012000400013

Kassari, M. C. M. (2016). Escola como espaço para a diversidade e o desenvolvimento humano. Educação \& Sociedade, 37(137), 1223-1240. https://doi.org/10.1590/es0101-73302016157049

Kind, L. (2004). Notas para o trabalho com a técnica de grupos focais. Psicologia em Revista, 10(15), 124-136.

Kittay, E. F., Jennings, B., \&Wasunna, A. A. (2005). Dependency, difference and the global ethic of longterm care. The Journal of Political Philosophy, 13(4), 443-469. https://doi.org/10.1111/j.1467-9760.2005.00232.x

Lima, V. M. M. (2012). A complexidade da docência nos anos iniciais na escola pública. Revista Nuances: Estudos Sobre Educação, 22(23), 148-166. https://doi.org/10.14572/nuances.v22i23.1767

Lisboa, C. S. M., \& Koller, S. H. (2001). Construção e validação de conteúdo de uma escala de percepção, por professores, dos comportamentos agressivos de crianças na escola. Psicologia em Estudo, 6(1), 59-69. https://doi.org/10.1590/S1413-73722001000100008

Louro, G. L. (2008). A construção da identidade profissional do professor: Uma análise de egressos do curso de Pedagogia. Congresso Português de Sociologia, Lisboa, Portugal, 6.

Louro, G. L. (2011). Educação e docência: Diversidade, gênero e sexualidade. Revista Brasileira de Pesquisa sobre Formação Docente, 3(4), 62-70.

Louro, G. L. (1997). Gênero, sexualidade e educação: Uma perspectiva pós-estruturalista. Rio de Janeiro, RJ: Vozes.

Louro, G. L.,\& Meyer, D. (1993). A escolarização do doméstico: A construção de uma escola técnica feminina (1946-1970). Cadernos de Pesquisa, (87), 45-57.

Maluf, A. C. M. (2003). Brincar, prazer e aprendizagem (2a ed.). Petrópolis, RJ: Vozes.

Magalhães, C. R. (2004). Escola e Família: mundos que se falam? Um estudo no contexto da implementação da Progressão Continuada (Tese de doutorado). Universidade Federal de São Carlos, São Carlos, SP, Brasil.

Mariano,M.S.S.,\&Muniz,H.P.(2006).Trabalhodocenteesaúde:Ocasodosprofessoresdasegundafasedoensinofundamental. Revista Estudos e Pesquisas em Psicologia, 6(1), 76-88. https://doi.org/10.1590/S0102-79722013000200022 
Marques, F. M., \& Sperb, T. M. (2012). A escola de educação infantil na perspectiva das crianças. Revista Psicologia: Reflexão e Crítica, 26(2), 414-421. https://doi.org/10.1590/S0102-79722013000200022

Masini, L. (2013). Uma nova criança exige uma nova escola. In C. A. L. Collares, M. A. Moysés, \& M. C. F. Ribeiro (Org), Novas capturas, antigos diagnósticos na era dos transtornos).(pp. 172-181). São Paulo, SP: Mercado das Letras.

Mattos, A. R., Pérez, B. C., Almada, C. V. R., \& Castro, L. R. (2013). O cuidado na relação professor-aluno e sua potencialidade política. Estudos de Psicologia, 18(2), 369-377.

Mello, G. N. (1985). Magistério de $1^{\circ}$ grau: Da competência técnica ao compromisso político. São Paulo, SP: Cortez.

Michels, M. A. (2006). Gestão, formação docente e inclusão: Eixos da reforma educacional brasileira que atribuem contornos à organização escolar. Revista Brasileira de Educação, 11(33), 406-421. https://doi.org/10.1590/S1413-24782006000300003

Moysés, M. A. A., \& Collares, C. A. L. (2014). Medicalização: O obscurantismo reinventado. In C. A. L. Collares, M. A. A. Moysés, \& M. C. F. Ribeiro (Org), Novas capturas, antigos diagnósticos na era dos transtornos (pp. 22-41). São Paulo, SP: Mercado das Letras.

Oliveira, C. F. B., \& Brito, L. M. T. (2013). Judicialização da vida na contemporaneidade. Psicologia: Ciência e Profissão, 33(esp), 78-89.

Oliveira, C. B. E., \& Marinho-Araújo, C. M. (2010). A relação família-escola: Intersecções e desafios. Estudos de Psicologia (Campinas), 27(1), 99-108. https://doi.org/10.1590/S0103-166X2010000100012

Oliveira, J. L. A. P., Bragnolo, R.I., \& Souza, S.V. (2014). Proposições metodológicas na intervenção com estudantes com queixa escolar. Psicologia Escolare Educacional, 18(3),477-484. https://doi.org/10.1590/2175-3539/2014/0183770

Passos, L. F. (2001). O projeto pedagógico e as práticas diferenciadas: O sentido da troca e da colaboração. In M. André (Org.), Pedagogia das diferenças na sala de aula (pp.107-131). Campinas, SP: Papirus.

Pinto, N., \& Morgado, J. (2012). Atitudes de pais e professores perante a inclusão. In Colóquio de Psicologia da Educação, Actas do 12 Colóquio de Psicologia da Educação (pp. 471-491). Lisboa: Instituto Universitário de Ciências Psicológicas, Sociais e da Vida.

Pletsch, M. D. (2009). Repensando a inclusão escolar: Diretrizes políticas, práticas curriculares e deficiência intelectual. Rio de Janeiro, RJ: EDUR.

Polonia, A. C., \& Dessen, M. A. (2005). Em busca de uma compreensão das relações entre família escola. Psicologia Escolar e Educacional, 9(2), 303-312. https://doi.org/10.1590/S1413-85572005000200012

Raposo, M., \& Maciel, D. A. (2005). As interações professor-professor na co-construção dos projetos pedagógicos na escola. Revista Psicologia: Teoria e Pesquisa, 21(3), 309-317.

Ribeiro, D. F., \& Andrade, A. S. (2006). A assimetria na relação entre família e escola pública. Revista Paidéia, 16(35), 385-394.

Rocha, C. (1996). Relação escolafamília: Da invisibilidade implícita a inevitabilidade da sua explicitação. Revista Educação Sociedade e Cultura, (6), 191-198.

Sawaia, B. B. (2002). Participação social e subjetividade. In M. Sorrentino (Ed.), Ambientalismo e participação na contemporaneidade (pp. 115-134). São Paulo, SP: EDUC.

Souza, M. P. R. (2006). Políticas Públicas de educação: Desafios, dilemas e possibilidades. In L. S. Viègas \& C. B. Angelucci (Orgs.), Políticas públicas em educação e psicologia escolar (pp. 129-149l). São Paulo, SP: Casa do Psicólogo.

Stelko-Pereira, A. C., Valle, J. E., \&Williams, L. C. A. (2015). Escala de engajamento escolar: Análise de características psicométricas. Revista de Avaliação Psicológica, 14(2), 207-212.

Tavares, C. M. M., \& Nogueira, M. O. (2013). Relação família-escola: Possibilidades e desafios para a construção de uma parceria. Revista Formação Docente, 5(1), 43-57. https://doi.org/10.15601/2237-0587/fd.v5n1p43-57

Varela, J. (1994). O estatuto do saber pedagógico. In T. T. da Silva (Org). O sujeito da educação: Estudos foucaultianos (pp. 86-96). Petrópolis, RJ: Vozes.

Vygotsky, L. S. (2000). A construção do pensamento e da linguagem. São Paulo, SP: Martins Fontes.

Vygotsky, L. S. (1991). A formação social da mente: O desenvolvimento dos processos psicológicos superiores (4a ed.). São Paulo, SP: Martins Fontes. 


\section{Luciane Guisso}

Doutoranda em Psicologia no Programa de Pós-Graduação de Psicologia da Universidade Federal de Santa Catarina (UFSC), Florianópolis - SC. Brasil.

E-mail lucianeguisso@yahoo.com.br

(iD https://orcid.org/0000-0002-4846-319X

Marivete Gesser

Doutora em Psicologia, professora de graduação e pós-graduação em Psicologia na Universidade Federal de Santa Catarina (UFSC), Florianópolis - SC. Brasil.

E-mail:marivete@ufsc.br

(iD https://orcid.org/0000-0002-4091-9754

Endereço para envio de correspondência

Rua Luiz Oscar de Carvalho, 75, Bloco A6, apto 34. CEP: 88036-400.

Trindade. Florianópolis - SC. Brasil.

Recebido 14/10/2017

Reformulado 28/03/2018 - 04/06/2018

Aceito 23/08/2018

Received 10/14/2017

Reformulated 03/28/2018 - 06/04/2018

Approved 08/23/2018

Recibido 14/10/2017

Reformulado 28/03/2018 - 04/06/2018

Aceptado 23/08/2018

Como citar: Guisso, L., \& Gesser, M. (2019). Docência e processos de escolarização: desafios nos anos iniciais do ensino fundamental. Psicologia: Ciência e Profissão, 39, 1-16. https:// doi.org/ 10.1590/1982-3703003186536

How to cite: Guisso, L., \& Gesser, M. (2019). Teaching and schooling processes: challenges in the early years of elementary school. Psicologia: Ciência e Profissão, 39, 1-16. https://doi.org/10.1590/1982-3703003186536

Cómo citar: Guisso, L., \& Gesser, M. (2019). Docencia y procesos de escolarización: desafíos en los años iniciales de la educación primaria. Psicologia: Ciência e Profissão, 39, 1-16. https://doi.org/10.1590/1982-3703003186536 